Espac. Saúde. 2021;22:e773

Doi 10.22421/1517-7130/es.2021v22.e773

(c) 2018 - ISSN 15177130

ARTIGO ORIGINAL

\title{
Percepção dos acadêmicos de saúde sobre atividades de extensão
}

\author{
Health students' perception of extension activities \\ Percepción de los académicos de salud sobre las actividades de extensión
}

Franciele Coutinho França ${ }^{1}$, Leide da Conceição Sanches ${ }^{2}$, Thiago Rocha da Cunha $^{3}$, Maria Cecilia Da Lozzo Garbelini ${ }^{4}$

\begin{abstract}
1 Mestre em Ensino nas Ciências da Saúde pela Faculdades Pequeno Príncipe. Curitiba, Paraná
2 Doutora em Sociologia pela Universidade Federal do Paraná. Docente do Programa de Mestrado em Ensino nas Ciências da Saúde da Faculdades Pequeno Príncipe. Curitiba, Paraná

3 Pós-doutor em Bioética Coordenador do Programa de Pós-Graduação em Bioética da Pontifícia Universidade Católica do Paraná (PUCPR). Curitiba, Paraná

4 Doutora em Ciências, Professora da Graduação e do Mestrado em Ensino nas Ciências da Saúde pela Faculdades Pequeno Príncipe. Curitiba, Paraná
\end{abstract}

\section{RESUMO}

A extensão permite a consolidação da aprendizagem e incentivo à formação de cidadãos críticos, com capacidade de enfrentar e solucionar questões individuais e sociais. Objetivou-se apreender a percepção dos alunos extensionistas frente a ações educativas em saúde. Tratase de um estudo exploratório descritivo com abordagem qualitativa. Participaram 15 alunos extensionistas de uma instituição de ensino superior localizada na cidade de Curitiba (PR). Para subsidiar a pesquisa foram desenvolvidas atividades preparatórias sobre alimentação

Autor de Correspondência:

*Franciele Coutinho França. E-mail: framnutri2011@hotmail.com 
saudável nos meses de agosto e setembro de 2018 e, no mês subsequente, a ação educacional foi apresentada, pelos extensionistas, para uma comunidade parceira. A coleta de informações foi efetivada por meio de entrevista individual e audiogravada. Deve-se considerar a amplitude da extensão em diversos âmbitos, conciliando teoria e prática, permitindo que visões acerca de mundos diferentes sejam repensadas e valorizadas.

Palavras-chave: Relações Comunidade-Instituição. Promoção da Saúde. Práticas interdisciplinares.

\begin{abstract}
Extension activities allow learners to consolidate learning and encourage the construction of critical citizens capable of facing and solving individual and social issues. The objective was to apprehend the perception by extension students of educational actions in the health area. This is an exploratory descriptive study with a qualitative approach. Fifteen extension students of a higher education institution located in Curitiba-PR participated in the study. To support the research, preparatory activities on healthy eating were developed in August and September, 2018, and, in the following month, the educational action was presented by the students to a partner community. The collection of information was accomplished through individual, audiorecorded interviews. The coverage of the extension course shall be considered in several areas, with conciliation of theory and practice, allowing views about different worlds to be rethought and valued.
\end{abstract}

Keywords: Community-Institution Relations. Health Promotion. Interdisciplinary Placement.

\title{
RESUMEN
}

La extensión permite la consolidación de aprendizajes y fomenta la formación de ciudadanos críticos, con capacidad para enfrentar y resolver problemas individuales y sociales. El objetivo fue conocer la percepción de los estudiantes de extensión sobre las acciones educativas en salud. Se trata de un estudio exploratorio descriptivo con abordaje cualitativo. Participaron quince estudiantes de extensión de una institución de educación superior ubicada en la ciudad de Curitiba - PR. Para apoyar la investigación, se desarrollaron actividades preparatorias sobre alimentación saludable en agosto y septiembre de 2018 y, en el mes siguiente, los extensionistas presentaron la acción educativa a una comunidad colaboradora. La recolección de información se realizó a través de entrevistas individuales y grabadas en audio. Se debe considerar el alcance de la extensión en varias áreas, combinando teoría y práctica, permitiendo repensar y valorar visiones sobre mundos diferentes.

Palabras clave: Relaciones Comunidad-Institucionales. Promoción de la Salud. Prácticas interdisciplinarias. 


\section{INTRODUÇÃO}

A extensão universitária é reconhecida como um dos três pilares da Educação Superior Brasileira, representando um importante espaço de formação e de aproximação entre a universidade e a sociedade. De acordo com a legislação, o tripé formado pelo ensino, pela pesquisa e pela extensão constitui o eixo fundamental da integração com a comunidade ${ }^{1}$.

As atividades de extensão constituem-se como uma possibilidade da instituição de ensino superior (IES) desempenhar sua autonomia didático-científica satisfazendo ao princípio da indissociabilidade entre ensino, pesquisa e extensão. Embora estas três funções básicas devam ser equivalentes e receber igualdade de tratamento por parte da IES a extensão é de modo geral pouco explorada, pois as atividades de ensino e pesquisa são mais evidenciadas².

Neste sentido, os dados advindos da extensão fornecem matéria-prima para a produção de novos conhecimentos em educação que são aplicáveis para a promoção e prevenção em saúde. Seguindo este raciocínio, os autores ${ }^{3}$ relatam que os projetos de extensão são de suma importância à medida que é possível perceber e reconhecer como a teoria pode ser desenvolvida e utilizada em determinados contextos diferentes para a comunidade não acadêmica.

O surgimento da extensão no Brasil deu-se no século passado, porém a extensão não é tão recente assim, pois em meados do século XIX na Inglaterra, aconteciam as primeiras manifestações sobre a temática, posteriormente expandindo-se para a Bélgica, Alemanha, Europa toda até chegar aos Estados Unidos ${ }^{4-5}$.

A primeira caracterização de extensão universitária no Brasil aconteceu em 1912, com a criação da Universidade Livre de São Paulo, e sua forma de apresentação acontecia mediante cursos e debates com pequena inserção da população, pois não correspondiam os interesses populares ${ }^{6}$.

Em abril do ano de 1931, por meio do decreto do Estatuto da Universidade Brasileira, criação do
Conselho Nacional de Educação (CNE) e o da Organização da Universidade do Rio de Janeiro (URJ), passou a serem discutidos os assuntos relacionados às questões sociais, a definição do modelo da universidade no Brasil, permitindo ao aluno participar do ensino de forma prática, e também a inerência da extensão com a sociedade.

A Lei de Diretrizes e Bases da Educação Nacional de $n^{\circ}$ 4024, promulgada em 21/12/1961, preconiza "as modalidades de transmissão do conhecimento e assistência"”. Esta foi a segunda legislação informada a respeito da educação com o objetivo de transferir a ciência e o assessoramento mediante a ordenação curricular para os três graus de ensino (primário, médio e superior) ${ }^{8}$.

A extensão universitária tornou-se obrigatória no ano de 1968 por meio da lei $\mathrm{n}^{\circ} 5540$, sancionada em 28/11/1968, que determina em seu Art. 20: "As universidades e os estabelecimentos isolados de ensino superior estenderão à comunidade, sob a forma de cursos e serviços especiais, as atividades de ensino e os resultados da pesquisa que lhes são inerentes" $", 9$.

Dentro dessa perspectiva o Ministério da Educação e Cultura (MEC) elaborou em abril de 1975 o Plano de Trabalho de Extensão Universitária, tendo como objetivo instituir "a extensão universitária no Brasil, como atividade sistemática e intimamente relacionada com o ensino e a pesquisa [...]", enfatizando e fortalecendo a indissociabilidade entre a tríade ensino, pesquisa e extensão ${ }^{10}$.

Em 06 de novembro de 1987 na Universidade de Brasília - UnB, por meio do I Encontro Nacional de Pró-Reitores de Extensão das Universidades Públicas a extensão foi redefinida com as práticas de ensino e pesquisa, tornando a mesma como processo na articulação do Ensino e Pesquisa. Diante do pressuposto, surgiu o Fórum de Pró-Reitores de Extensão das Universidades Públicas Brasileiras - Forproex, estabelecendo novos conceitos a extensão ${ }^{11}$. 
Figura 1 - A História da Extensão Universitária.

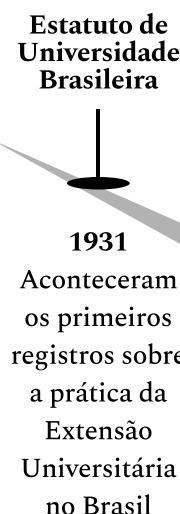

Fonte: Os autores, 2019.
Lei de

Diretrizes e

Bases da

Nacional no

4024
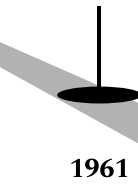

Foram preconizadas ações que envolviam a transmissão e assistência do conhecimento

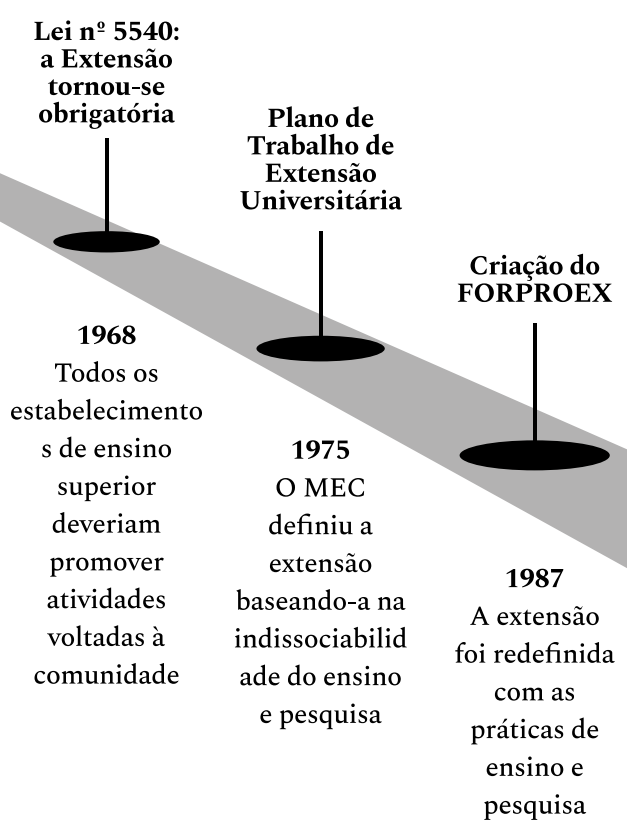

No final do ano de 1996 foi estabelecida a Lei ${ }^{\circ}$ 9394 de Diretrizes e Bases da Educação Nacional, dando direito a todo cidadão de ter acesso gratuito ao ensino fundamental e médio, além de determinar as obrigações das IES e dos profissionais da educação. As diretrizes curriculares básicas, dentre outros objetivos, sublinham a promoção da extensão compartilhada com a comunidade e projetos de pesquisa científica ${ }^{12}$.

Como avanço em 2001 foi aprovado o Plano Nacional de Educação o qual consolida que "no mínimo $10 \%$ do total de créditos exigidos para a graduação no ensino superior no País será reservado para a atuação dos estudantes em ações extensionistas", sendo a ponte para o crescimento e desenvolvimento de ambas as partes "universidade - comunidade", oportunizando a troca de saberes, crescimento pessoal e profissional ${ }^{11}$.

Recentemente o MEC estabeleceu as Diretrizes para a Extensão na Educação Superior Brasileira, na forma de componentes curriculares para os cursos de graduação, pela Resolução $\mathrm{n}^{\circ}$ 7, em dezembro de 2018 (Figura 1). O Art. $2^{\circ}$ regulamenta as ações extensionistas que se vinculam à formação 
dos estudantes, conforme descritas nos Planos de Desenvolvimento Institucionais (PDIs) e nos Projetos Políticos Institucionais (PPIs) das entidades educacionais, de acordo com o perfil do egresso estabelecido nos Projetos Pedagógicos dos Cursos (PPCs) e nos demais documentos normativos próprios ${ }^{13}$.

Justifica-se a pesquisa pela relevância da formação de profissionais que articulam o conhecimento científico, advindo do ensino e da pesquisa, com oportunidade de interação e transformação na qualidade de vida do público externo.

Assim, por meio da atividade de extensão, objetivouse apreender a percepção dos estudantes frente à ação educativa em saúde junto a uma comunidade de idosas.

\section{MÉTODO}

Trata-se de um estudo exploratório descritivo com abordagem qualitativa, realizado com acadêmicos extensionistas de uma IES localizada em Curitiba PR.

Participaram da pesquisa 15 graduandos, matriculados em diversos cursos da área da saúde, participantes do projeto de extensão Educar para Prevenir. O projeto existe desde 2009 e tem o foco na promoção da educação em saúde. Para subsidiar a pesquisa foram desenvolvidas atividades preparatórias sobre alimentação saudável, para um grupo de idosas, nos meses de agosto a setembro de 2018. A apresentação da ação educacional aconteceu no mês subsequente, em um único encontro com o público-alvo, com o objetivo de trabalhar a saúde nutricional e questionamentos comuns decorrentes da alimentação envolvendo patologias próprias à idade como hipertensão e diabetes.

Após a conclusão da atividade educacional, os extensionistas foram convidados a participar da pesquisa, efetivada nas dependências da IES. A coleta das informações foi efetivada com a aplicação de um instrumento contendo questões sociodemográficas seguido de uma entrevista semiestruturada, individual e audiogravada, previamente agendada com os discentes. Para a seleção dos participantes da pesquisa seguiram-se os critérios: alunos que estivessem regularmente matriculados na IES, maiores de 18 anos, que participaram das reuniões realizadas nos meses de agosto a setembro de 2018 e colaborado em todas as fases do preparo e da apresentação da tarefa educativa. A participação foi voluntária e os participantes foram identificados por códigos para preservar o anonimato (P1, P2...P15). A pesquisa atendeu aos preceitos da Resolução 446/12, do Conselho Nacional de Saúde ${ }^{14}$, com aprovação pelo Comitê de Ética em Pesquisa, sob o Parecer Consubstanciado no 2.827.939.

Para a apreciação das entrevistas utilizou-se Análise de Conteúdo, seguindo os critérios metodológicos que compreendem os seguintes passos: organização das informações coletadas por meio das questões respondidas; leitura e releitura do material, na tentativa de, constantemente, retomar o objetivo inicial do trabalho, além do contato exaustivo com os dados ${ }^{15}$.

\section{RESULTADOS}

A ação extensionista referente à alimentação saudável foi desenvolvida com a soma das experiências dos envolvidos, extensionistas e público-alvo, no sentido de estimular hábitos saudáveis, melhorar as condições de saúde e desenvolver o senso de responsabilidade pela própria saúde. Permitiu conhecer o público-alvo e pela interação dialógica houve respeito e promoção da interculturalidade.

Dentre os participantes da pesquisa, 11 eram do gênero feminino; nove estavam na faixa etária entre 20 a 25 anos; 13 eram de etnia branca e dois pardos. Quanto aos períodos dos cursos de graduação, um 
aluno cursava o primeiro período; cinco cursavam o segundo período; um frequentava o terceiro período; dois estavam matriculados no quarto período e seis eram estudantes do quinto e sexto períodos.

Após a transcrição das entrevistas e análise por meio da leitura e releitura das entrevistas, com foco na questão norteadora e objetivo da pesquisa, buscando a percepção dos estudantes sobre a vivência na extensão durante a formação acadêmica, obtiveramse as seguintes categorias: Atividades extensionistas na formação acadêmica: pontos positivos e fragilidades; Atividades de extensão e educação em saúde; Prática interdisciplinar e interprofissional na articulação dos saberes e fazeres; Contribuição da Extensão no desenvolvimento pessoal e profissional dos acadêmicos e Período da inserção dos alunos em atividade de extensão.

\section{Atividades extensionistas na formação acadêmica: pontos positivos e fragilidades}

Foi possível identificar a relevância do projeto de extensão não só no âmbito acadêmico, mas também no contexto pessoal com contribuição para o amadurecimento do futuro profissional que a IES lançará ao mercado de trabalho. Os extensionistas tiveram a oportunidade de aprimorar suas habilidades quanto à comunicação, interação social e inserção na comunidade, juntamente com os colegas dos diversos cursos da saúde integrados ao projeto.

O ponto positivo é isso: desenvolve muito o aluno, você acaba crescendo por ter o contato com as pessoas e também por desenvolver as apresentações [...] antes de apresentar um tema a gente tem que estudar todo o tema, por mais que a gente não faça a apresentação né (P4).

Quando indagados sobre as fragilidades relacionadas à sua participação no projeto de extensão pode-se observar menor ênfase quando confrontadas aos pontos positivos.

[...] os pontos negativos eu acho que, não sei se é muito um ponto negativo, mas tem que ter certo comprometimento né, nesse horário que é fora do horário de aula, praticamente isso, e você tem que adequar a linguagem (P11).

\section{Atividades de extensão e educação em saúde}

Nesse contexto, pode-se observar nas entrevistas que o conhecimento adquirido é capaz de transcender a lacuna universidade/comunidade, diante da construção do saber incorporada à universidade, propiciando transmitir ao meio externo ações preventivas sobre diversas temáticas.

Ah eu acho muito importante, porque você não consegue fazer saúde só curando, só dando remédio, você tem que fazer a conscientização da população [...] eles têm um conhecimento também para agir de uma forma correta (P5).

\section{Prática interdisciplinar e interprofissional na articulação dos saberes e fazeres}

O trabalho em equipe, com vários profissionais da área da saúde, proporciona a interação entre os diferentes conhecimentos técnicos específicos com a produção de uma proposta de intervenção que não seria produzida por nenhum dos profissionais isoladamente. A interdisciplinaridade traz uma visão ampla frente a diversas configurações do contexto inserido, além de oportunizar a formação de um rico conteúdo final.

\footnotetext{
[...] é fantástico, quando dá certo, quando tem um diálogo entre esses profissionais e todos estão dispostos realmente a trabalhar em conjunto [...] eu acho que se torna enriquecedor para a pessoa e para mim como estudante sabe, eu aprender a ver o outro lado, então a ver o mundo da psicologia, da farmácia, da biomedicina como eles enxergariam aquela situação (P3).
}

\section{Contribuição da Extensão no desenvolvimento pessoal e profissional dos acadêmicos}

As falas a seguir denotam a contribuição da extensão 
no desenvolvimento pessoal e profissional dos participantes, ganhando um espaço favorável frente à prática, reforçando e aprimorando ainda mais a interação junto à comunidade.

[...] foi a partir do projeto que eu perdi o medo de falar na frente do público e tudo mais, justamente por ser um ambiente mais informal [...] foi uma oportunidade muito grande para eu aprender a lidar com a timidez, desenvolver um pouco mais a minha fala, sem contar que você pensar em levar um conteúdo muito relevante para outros lugares fora daqui, para pessoas que às vezes não tem a oportunidade (P6).

\section{Período da inserção dos alunos em atividades de extensão}

Foi possível observar que os acadêmicos podem se inserir em ações extensionistas já no primeiro período e permanecer até o final da graduação. O início precoce do graduando na extensão sem dúvida permitirá um rico aprendizado tanto na sua formação profissional ou pessoal.

[...] eu entrei quando eu estava no primeiro periodo eu já estava ajudando, isso me ajudou bastante a entender [...] eu acho que sim é muito importante [...] no começo e fim, no começo você tem que ser guiado e no fim você tem que tipo confirmar o que você aprendeu (P1).

Privilegia-se no estudo a extensão como um facilitador na aproximação com a comunidade, contribuindo com a formação acadêmica cidadã estabelecida pela vivência e valorização do conhecimento interprofissional e interdisciplinar.

\section{DISCUSSÃo}

A extensão universitária no Brasil teve forte influência de Paulo Freire, quando sua consideração frente à temática se estendeu ao campo da extensão, de forma a compreender que esta permite uma oportunidade de aprendizagem mútua, envolvendo a "universidade com a comunidade" e a "comunidade com a universidade" ${ }^{16}$. De acordo com o autor ${ }^{17}$, a extensão é uma prática educativa libertadora que permite a construção do conhecimento a partir de um diálogo de saberes, ou seja, permite ao extensionista levar a teoria trabalhada em sala de aula até a comunidade, por meio da prática, reforçando a aprendizagem dialogada.

Durante o desenvolvimento do estudo foi possível observar a relevância da extensão quando os alunos foram indagados sobre Atividades extensionistas na formação acadêmica: pontos positivos e fragilidades.

Os projetos de extensão oferecem aos acadêmicos uma formação mais consistente, pois incentivam o desenvolvimento de seres críticos e capazes de atender demandas sociais e individuais em âmbitos distintos ${ }^{18}$. Em concordância ao pressuposto, os colaboradores do estudo ${ }^{19}$ apontam diferentes competências que a extensão oferece aos alunos durante a graduação, tais como a correlação da teoria com a prática por meio do diálogo, troca de conhecimentos adquiridos na universidade e a aproximação dos mesmos com parte da sociedade que não tem acesso à educação.

Em entrevista à Revista Brasileira de Extensão Universitária, faz menção da importante participação dos acadêmicos em projetos de extensão, dizendo que esta atividade é expressiva na formação enquanto cidadão, formação enquanto pessoa para a sociedade e com a sociedade ${ }^{20}$. Ainda nesse contexto, a inserção de graduandos em projetos de extensão proporciona um aprimoramento em sua formação, ao desenvolver habilidades de participação e proatividade, que possibilitam a compreensão e o interesse frente às atividades que devem ser delineadas e alcançadas ${ }^{21}$.

Com respeito às limitações, estudo sobre a participação dos alunos em projeto de extensão ${ }^{22}$ enfatiza aspectos relacionados à falta de interesse e comprometimento: “[...] nossas agendas e horários 
não se batem, além de alguns alunos que não tem compromisso e acabam faltando demais". Ainda sobre as fragilidades supramencionadas, os autores relatam que podem refletir negativamente no andamento das atividades extensionistas, pois o estudante deve ter papel fundamental em todos os estágios das atividades propostas que abrange desde a idealização, organização até o conteúdo final.

No presente estudo foi possível destacar algumas barreiras e limitações apontadas no desenvolvimento das atividades de extensão tais como: a falta de tempo para se dedicar ao projeto e os horários das atividades em contraturno. Ainda foi relatada a falta de interesse de alguns alunos e a necessidade de adequação da comunicação para as diferentes faixas etárias.

A segunda categoria, Atividades de extensão e educação em saúde, vem de encontro à Resolução $\mathrm{n}^{\circ}$ 7, estabelecida pelo MEC, que no Art. 5ํ e inciso I estrutura a concepção e a prática das Diretrizes da Extensão na Educação Superior frente "a interação dialógica da comunidade acadêmica com a sociedade por meio da troca de conhecimentos, da participação e do contato com as questões complexas contemporâneas presentes no contexto social”"13.

Uma resenha do livro "Conscientização: teoria e prática da libertação: uma introdução ao pensamento de Paulo Freire", escrito em 1979 por Paulo Freire, enfatiza a importância do diálogo e da educação libertadora com o propósito de formar um indivíduo consciente, capaz de construir sua história e interagir com o mundo por meio das esferas culturais e sociais ${ }^{23}$. Portanto, faz-se necessário que todos se conscientizem que para saber relacionarse com o mundo, não deve haver uma relação de submissão e sim de ação, ou melhor, só é possível uma visão transformadora da realidade quando se tem consciência do mundo em sua volta.

A promoção da saúde foi apresentada pela primeira vez em 1945, por Henry Sigerist, no Canadá, com destaque dentre as quatro áreas mais importantes da medicina. Já em 1970 destaca-se o 'Informe Lalonde' que propõe e prioriza "medidas preventivas e programas educativos voltados para as mudanças comportamentais e estilos de vida" ${ }^{24}$. No entanto, não foi dado enfoque aos determinantes socioeconômicos e políticos e, deste modo, a promoção de saúde obteve seu destaque na saúde pública a partir da década de 1980, por meio de acontecimentos internacionais ${ }^{25}$.

Para trabalhar a educação em saúde na comunidade, acredita-se que seja necessário resgatar a educação popular, um ponto de partida para a troca de experiências dos extensionistas com a comunidade. É preciso ter acesso e entender aos diferentes pontos de vista, conhecer como a comunidade atua em relação a sua saúde, valorizar os valores populares e, assim, poder contribuir com a aprendizagem dialógica buscando a reflexão crítica sobre os problemas que os cercam ${ }^{26}$.

É possível compreender a importância das atividades extensionistas, uma vez que essa prática possibilita o desenvolvimento da teoria junto à prática, sendo uma amplitude para a construção de conhecimento e contribuição para "a compreensão de um ser socialmente responsável e capaz de refletir acerca das vivências cotidianas, construindo a sua identidade, tanto pessoal quanto profissional, sustentada na busca contínua do saber" ${ }^{27}$.

$\mathrm{Na}$ terceira categoria, Prática interdisciplinar e interprofissional na articulação dos saberes e fazeres, apreende-se que a atividade de extensão permite a integração dos extensionistas estabelecendo entrada para a interdisciplinaridade, com o intuito de possibilitar aos participantes o compartilhamento de conhecimentos, diferentes pontos de visão, habilidades e construções de ações com um olhar voltado para a sociedade. Assim há o rompimento do pensar de forma individual, com avanço e contribuição para o desenvolvimento pessoal e social.

Sob o ponto de vista de $\operatorname{Lorandi}^{28}$, as ações extensionistas estimulam as práticas sociais e "por 
ser uma ação interdisciplinar permite, ou exige, a resolução dos conflitos derivados de relações dialógicas entre sujeitos detentores de diferentes saberes e poderes [...]".

Em contrapartida, para o autor os acadêmicos da área de saúde adquirem escassos ou nenhum conhecimento a respeito da atuação em equipes multiprofissionais, ações interdisciplinares e saúde coletiva. Relata ainda que o que se observa no Brasil, de um modo geral, é a quantidade elevada de cursos na área de saúde sendo criados com fácil acesso, admitindo o ingresso de alunos às universidades sem considerar o caráter qualitativo da formação ${ }^{29}$.

\section{$\mathrm{Na}$ categoria Contribuições da Extensão no} desenvolvimento pessoal e profissional dos acadêmicos, observa-se a contribuição da extensão para o desenvolvimento pessoal e profissional dos participantes com destaque para um espaço favorável frente à atividade prática reforçando e aprimorando ainda mais a interação junto à comunidade.

Na visão de Paulo Freire, a extensão assegura ao aluno o desenvolvimento do processo do ensino e aprendizagem por meio de um ensino crítico, permitindo a participação na construção diante da prática educativa ${ }^{17}$.

Reitera-se que a extensão é um ambiente oportuno para o conhecimento, considerando o contato com diferentes instituições e comunidades. É a interação entre a universidade e a sociedade que permite ao acadêmico o desenvolvimento de "trabalhos, técnicas, habilidades que favoreçam sua formação e obtenção de informações, que servirão de auxílio em suas práticas educativas e de saúde" ${ }^{30}$. Isso vem ao encontro do estudo de Moron $^{31}$, que registra a relevância da extensão para a formação acadêmica e para a vida pessoal, como oportunidade de aplicar na prática os conteúdos apreendidos na teoria e, também, o constante aprendizado com os demais participantes, sejam estes professores, colegas de graduação ou comunidade.
A extensão permite comparar os saberes teóricos adquiridos ou mesmo os conhecimentos que ainda serão descobertos pelo ensino. Destaca também a importância da pesquisa, pois esta é capaz de expandir a evolução intelectual dos alunos, ao reforçar a importância da indissociabilidade entre ensino, pesquisa e extensão ${ }^{32}$. Dando sequência, a interação dos acadêmicos com idosos institucionalizados contribuiu para a "formação cidadã dos alunos, haja visto que durante as atividades os mesmos precisaram praticar algumas habilidades específicas de comunicação com um público de outra geração e exercitar as instruções recebidas com relação ao manejo $[\ldots]]^{\prime 3}$.

Quando o acadêmico tem contato com atividades baseadas no ensino, pesquisa e extensão, a sua base profissional será diferenciada, permitindo levar consigo uma bagagem de experiências distintas daquela que se prende somente ao tradicionalismo. Assim, o contato com problemas que necessitam de resoluções forma cidadãos e profissionais mais estruturados para semear o conhecimento adquirido e contribuir com o mundo fora da universidade ${ }^{34}$.

A importância da participação dos acadêmicos nas atividades extensionistas permite o desenvolvimento dos mesmos no âmbito pessoal e profissional, bem como, o vínculo entre universidade e comunidade, a relação com profissionais de áreas variadas de conhecimento e a ampliação do conhecimento na sua futura profissão por meio das ações práticas realizadas ${ }^{35-36}$

Partindo desta visão, observa-se que o acadêmico de coadjuvante passa a protagonista do cenário externo ao qual foi inserido. Transcende a teoria e delimitação do espaço físico dentro da universidade, ao mesmo tempo em que permite, em outra dimensão e estrutura, atender a demanda da sociedade com ênfase na dimensão dos quatro pilares da educação: o "aprender a aprender", o "aprender a fazer", o "aprender a conviver", e o "aprender a ser" ${ }^{37}$.

Relatos da última categoria, Período da inserção 
dos alunos em atividade de extensão, denotam que as ações extensionistas podem ser iniciadas já no primeiro período estendendo-se até o final da graduação. $\mathrm{O}$ início precoce do graduando neste tipo de atividade sem dúvida permitirá um rico aprendizado, tanto na sua formação profissional ou pessoal.

A importante disseminação da extensão e suas atividades promovidas a cada dia transpassam fronteiras. Esta prática extensionista, que antes era restrita aos finais de semana e sem recurso financeiro ou operacional, hoje prossegue por caminhos que superam as suas fronteiras e permeiam as universidades ${ }^{38}$.

Conforme o relato da autora, o contato com a extensão foi já no primeiro período da graduação e desde então não se afastou, pois permitiu a aproximação com a educação em saúde, uma das estratégias da promoção da saúde, com finalidade de diminuir a miséria e as desigualdades no Brasil. Descreve que o momento ideal para o envolvimento com projetos de extensão deve ser no início da graduação, uma vez que esta proporciona o contato não só com a teoria, mas também com a prática ${ }^{39}$. Corroborando com o relato supracitado, acredita-se que a extensão contribui para o processo de aprendizagem, envolvendo o aluno com a prática que tem a realizar. Destaca-se ainda que depois de seis meses de participação no Programa de Extensão Universitária Rede Incluir, o extensionista não apresenta as mesmas perspectivas observadas durante o início do curso ${ }^{40}$.

A vivência dos extensionistas em projetos socioeducativos sobre os cuidados com a saúde, com interação entre o brincar e a humanização, culminando na promoção da autoestima, da conscientização e da cidadania nas comunidades é de extrema relevância ${ }^{41}$.

Ao completar a temática neste estudo, destaca-se que apenas um dos pesquisados se encontrava no primeiro período e cinco dos participantes cursavam o segundo período. Diante deste dado, pareceu escasso o ingresso dos discentes iniciantes neste projeto de extensão. Constata-se que é necessária uma maior sensibilização dos alunos do primeiro período quanto à divulgação de todos os projetos de extensão oferecidos pela IES. Fica também o questionamento se seria falta de interesse, por parte dos acadêmicos, em participar das atividades extensionistas no início dos cursos de graduação.

\section{CONCLUSÕES}

Foi possível notar a relevância da extensão para os acadêmicos inseridos no projeto de extensão Educar para Prevenir. Percebeu-se a amplitude que a mesma traz em diversos âmbitos, pois apreender a teoria conciliando-a com a prática permite que visões acerca de mundos diferentes sejam repensadas e valorizadas, acolhendo a cultura e opiniões extrauniversidade.

Percebe-se que a extensão, como via de mão dupla, contribui para a formação dos acadêmicos, permite que a academia partilhe com diferentes cenários o saber científico adquirido por meio do ensino e da pesquisa e, ainda, oportuniza a prática de habilidades de comunicação com os diferentes públicos, desenvoltura que alguns alunos poderão não desenvolver ao longo da graduação, sem o exercício da extensão.

É notória a necessidade do incentivo à participação dos acadêmicos em ações extensionistas educativas, processos interdisciplinares que articulam permanentemente o ensino e a pesquisa, com o propósito de interação entre a IES e outros setores da sociedade. No entanto, para a execução da extensão, algumas barreiras e limitações devem ser transpostas como a falta de tempo, realização das atividades em contraturno, falta de interesse de alguns alunos e necessidade de adequação na comunicação dialógica. Acredita-se que o estudo seja uma contribuição para futuras pesquisas acerca da extensão universitária, 
associando e fortalecendo o elo entre os pilares da educação: aprender a conhecer, aprender a fazer, aprender a viver com os outros e aprender a ser.

\section{REFERÊNCIAS}

1. Barragán TO, Rodrigues GS, Spolaor GC, Bortoleto MAC. O papel da extensão universitária e sua contribuição para a formação acadêmica sobre as atividades circenses. Pensar a Prática. 2016;19(1).

2. Moita FMGSC, Andrade FCB. Ensino-pesquisaextensão: um exercício de indissociabilidade na pósgraduação. Universidade Federal da Paraíba, Departamento de Fundamentação da Educação. Rev Bras Educ. 2009;14(41).

3. Posser J, Pedroso D. Ensino, Pesquisa e Extensão: a Educação em Saúde como ferramenta para prevenção de parasitoses. Cataventos. 2016;8(1):74-89.

4. Paula JA. A extensão universitária: história, conceito e propostas. Interfaces - Rev de Extensão. 2013;1(1):05-23.

5. Deslandes MS, Arantes AR. A extensão universitária como meio de transformação social e profissional. Sinapse Múltipla. 2017;6(2):179-83.

6. Barbosa VC. Extensão Universitária: proposição e validação de um instrumento de avaliação da percepção dos discentes. [Dissertação]. Fundação Mineira de Educação e Cultura/ Faculdade de Ciências Empresariais. Belo Horizonte; 2012.

7. Medeiros MM. A Extensão Universitária No Brasil - Um Percurso Histórico. Revista Barbaquá - UEMS. 2017;(1):09-16.

8. Brasil. Ministério da Educação. Lei n. 4.024, de 20 de dezembro de 1961. Fixa as Diretrizes e Bases da Educação Nacional. Brasília; 1961.

9. Brasil. Lei n. 5.540, de 28 de novembro de 1968. Fixa normas de organização e funcionamento de Ensino Superior e sua articulação com a escola média, e dá outras providências. Brasília; 1968.

10. Souza PH, Moreira DS, Souza MMP. Uma breve descrição da Extensão Universitária na UNIFAL - MG.
Interfaces - Rev de Extensão. 2014;2(2):17-35.

11. Forproex. Fórum de Pró-Reitores de Extensão das Universidades Públicas Brasileiras. Política Nacional de Extensão Universitária. p. 68, 2012.

12. Brasil. Senado Federal. Lei de Diretrizes e Bases da Educação Nacional. Brasília;2005.

13. Brasil. Ministério da Educação. Resolução 7/2018. Estabelece as Diretrizes para a Extensão na Educação Superior Brasileira. Brasília; 2018.

14. Brasil. Ministério da Saúde. Resolução 466/2012 do Conselho Nacional de Saúde, que institui Diretrizes e Normas Regulamentadoras das Pesquisas envolvendo seres humanos. Brasília; 2012.

15. Minayo MCS. O desafio do conhecimento: Pesquisa Qualitativa em Saúde. 10ª ed. São Paulo: Hucitec-Abrasco; 2007.

16. Forproex. Fórum de Pró-Reitores de Extensão das Universidades Públicas Brasileiras. Avaliação da Extensão Universitária: práticas e discussões da Comissão Permanente de Avaliação da Extensão. Organização: Maria das Dores Pimentel Nogueira. Belo Horizonte, 2013.

17. Freire P. Extensão ou comunicação? $8^{\underline{a}}$ ed. Rio de Janeiro: Paz e Terra; 1985.

18. Del-Masso MCS, Roveda JAF, Zuanon ACC, Galhardo E. Interdisciplinaridade em extensão universitária. Rev Ciênc Ext. 2017;13(3):2-12.

19. Nobre RS, Moura JRA, Brito GR, Guimarães MR, Silva ARV. Vivenciando a extensão universitária através de ações de educação em saúde no contexto escolar. Extensão Educação em Saúde. 2017;20(2): 288-92.

20. Santos AB. As ações de extensão universitária da modalidade Rondon. Entrevista concedida a Geraldo Ceni Coelho. Revista Brasileira de Extensão Universitária. 2015;6(2):103-08.

21. Sousa BS, Andrade AP, Sales Filho RF, Sousa ILL, Silva FG, Gonçalves KG. A contribuição da extensão universitária no serviço de assistência pré-hospitalar. Revista Nursing. 2019;(22): 2741-44.

22. Ribeiro MA, Cavalcante ASP, Albuquerque IMN, Vasconcelos MIO. A extensão universitária na perspectiva 
de estudantes de cursos de graduação da área da saúde. Interagir: pensando a Extensão.2016: 55-69.

23. Borges GFS, Freire P. Conscientização: teoria e prática da libertação: uma introdução ao pensamento de Paulo Freire. Trad. de Kátia de Mello e Silva. São Paulo: Cortez \& Moraes, 1979. Criar Educação. 2018;7(2).

24. Silva JG, Gurgel AA, Frota MA, Vieira LJES, Valdés MTM. Promoção da saúde: possibilidade de superação das desigualdades sociais. Rev Enferm. 2008;16(3):421-25.

25. Carvalho FFB, Cohen SC, Akerman M. Refletindo sobre o instituído na Promoção da Saúde para problematizar “dogmas”. Saúde em Debate. 2017;41(3):265-76.

26. Freire P, Nogueira A. Que fazer: Teoria e prática em educação popular. 4ª ed. Petrópolis: Vozes;1993.

27. Freitas TPP, Paula CC, Zanon BP, Meirelles FSC, Weiller TH, Padoin SMM. Contribuições da extensão universitária na formação de acadêmicos de enfermagem. Rev Enferm. 2016;6(3):307.

28. Lorandi PA. Extensão Universitária como Responsabilidade Social: análise de uma prática Paulo Angelo Lorandi. Rev Even Pedagóg. 2016;(1):148-67.

29. Pinho MCG. Trabalho em equipe de saúde: limites e possibilidades de atuação eficaz. Revista Ciência e Cognição. 2006;(8):68-87.

30. Oliveira FLB, Almeida Júnior JJ. Extensão universitária: contribuições na formação de discentes de Enfermagem. Rev Bras Pesq Saúde. 2015;17(1):19-24.

31. Moron VB, Pinto AS, Konrath M. Formação Profissional Em Saúde: Perspectivas Interdisciplinares no Projeto de Extensão "Saúde em Ação". Revista Conhecimento Online. 2018;(2):179-91.

32. Puhl MJ. O conhecimento e o princípio da indissociabilidade entre ensino. Revista HISTEDBR Online. 2016:222-32.
33. Oliveira JHS, Lima DC, Fernandes LA, Pereira AA, Fernandes CA. Envelhecer com qualidade: reflexo de ações extensionistas em instituições asilares. Rev Ciênc Ext. 2016;12(2):141-52.

34. Lima AF, Rodrigues EGO, Santos VMM, Nery AMF, Sousa JT. A importância do Ensino, Pesquisa e Extensão na formação profissional. II Jornada Ibero-Americana de Pesquisas em Políticas Educacionais e Experiências Interdisciplinares na Educação. 2017:1586-97.

35. Martins SN, Eckhardt VMT, Valandro NA, Costa J. A Contribuição da Extensão na Formação de Universitários: um estudo de caso. Revista NUPEM. 2015; 7(12):193-207.

36. Menegon RR, Gouveia Júnior SA, Lima MRC, Lima JM. Projetos de Extensão: Um Diferencial para o Processo de Formação. Colloquium Humanarum. 2013;(10):1268-74.

37. Martins EF. Extensão como componente curricular: oportunidade de formação integral e de solidariedade. Ciências e Cognição. 2008;13(20): 201-9.

38. Deus SFB. A extensão universitária e o futuro da universidade. Revista Espaço Pedagógico. 2018;25(3): 62433.

39. Silva MBT. Inserção do acadêmico de enfermagem em atividades de pesquisa e extensão universitária. [Tese]. Instituto Oswaldo Cruz, Rio de Janeiro; 2017.

40. Resende CC, Gonçalves ACC, Santos EP, Vaz GS, Faleiro LRM. Aprender a Incluir: o papel da extensão universitária na perspectiva de alunos extensionistas do Programa Rede Incluir. Revista Interdisciplinar de Extensão. 2018;(2):121-32.

41. Conchão S. Extensão Universitária na Faculdade de Medicina do ABC: quais avanços e limites? ABCS Health Sci. 2015;40(3):318-23. 